\title{
Effects of fermented wheat-rice distillers dried grains with solubles on meat quality and amino acid profile in broilers
}

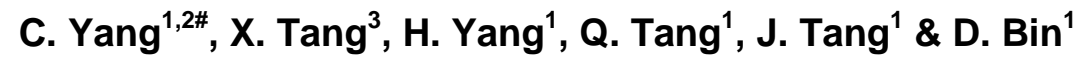 \\ ${ }^{1}$ College of Life Sciences and Environment, Hengyang Normal University, Hengyang 421008, Hunan, P. R. China \\ ${ }^{2}$ Hunan International Joint Laboratory of Animal Intestinal Ecology and Health, Laboratory of Animal Nutrition and Human \\ Health, College of Life Sciences, Hunan Normal University, Changsha 410081, Hunan, P. R. China \\ ${ }^{3}$ College of Bioengineering, Hunan Vocational Technical College of Environment and Biology, Hengyang 421005, \\ Hunan, P. R. China
}

(Received 24 January 2019; Accepted 27 March 2019; First published online 18 November 2019)

Copyright resides with the authors in terms of the Creative Commons Attribution 4.0 South African License.
See: http://creativecommons.org/licenses/by/4.0/za
Condition of use: The user may copy, distribute, transmit and adapt the work, but must recognize the authors and the South African
Journal of Animal Science.

\begin{abstract}
The aim of this experiment was to evaluate the effects of replacing distillers dried grains with solubles (DDGS) with fermented DDGS (FDDGS) on meat quality and serum amino acid profiles in Chinese yellow broilers. Forty-eight 42-day-old male Chinese yellow broilers were randomly allotted to the treatments. Each treatment was replicated six times with four birds per replicate. Both groups received a basal corn-soybean diet that was supplemented with either $20 \%$ DDGS or $20 \%$ FDDGS. Broilers were euthanized at 70 days old. The right half of each breast was evaluated for meat quality. Both breast and thigh meats were evaluated for proximate and fatty acid composition. Serum from blood samples was analysed to quantify relative amounts of free amino acids. Breast meat from broilers supplemented with FDDGS had a lower pH and less drip loss than those supplemented with DDGS $(P<0.05)$. No differences were detected between treatments in the proximate composition of breast and thigh meat $(P>0.05)$. Myristic acid $(\mathrm{C} 14: 0)$ concentration of thigh muscles was reduced for broilers supplemented with FDDGS compared with those supplemented with DDGS $(P<0.05)$. Concentrations of lysine, taurine, alpha-aminoadipic acid, glycine, and 3-methylhistidine in serum were all lower for broilers supplemented with FDDGS than for those supplemented with DDGS $(\mathrm{P}<$ 0.05). Meanwhile, the serum phosphoserine concentration of the FFDS-supplemented broilers was greater than those supplemented with DDGS $(P<0.05)$. In conclusion, replacing $20 \%$ DDGS with a like amount of FDDGS can be recommended for diets of growing broiler chickens.
\end{abstract}

Keywords: fatty acids, meat quality, shear force

\#Corresponding author: yangcansky@163.com

\section{Introduction}

As ethanol production has expanded in recent years, the availability of DDGS as a feedstuff for poultry diets has increased. Owing to the high percentage of lignocellulose and low quality of protein (Barekatain et al., 2013), effective utilization of DDGS remains an elusive problem in animal production. For poultry, DDGS can be included as $10 \%$ to $15 \%$ of their diet without reducing product quality (Shim et al., 2011). However, production efficiency was shown to decrease when the concentration of DDGS exceeded 18\% (Abudabos et al., 2017b). Schilling et al. (2010) observed that broilers whose diets were supplemented with 18\% and 24\% DDGS produced breast meat with higher $\mathrm{pH}$ and shear force compared with a control treatment.

Palmitic acid, oleic acid and linoleic acid are the predominant fatty acids in DDGS, comprising as much as $21.05 \%, 22.12 \%$, and $49.92 \%$ of the total fatty acid content, respectively (Abudabos et al., $2017 \mathrm{a}$ ). The evaluated linoleic acid of DDGS improved meat quality by increasing the proportion of polyunsaturated fatty acids (PUFAs) (Min et al., 2015; Jiang et al., 2014). However, PUFAs are vulnerable to lipid peroxidation (Stein \& Shurson, 2009). Feeding DDGS that contain oxidized lipids may induce oxidative stress, alter immune function and, thus, negatively affect animal growth performance. 
Solid-state fermentation has been utilized to improve the nutritional value of agricultural by-products. Fermentation loosens the structure of lignocellulose and makes the nutrients in DDGS more accessible to animals. Microorganisms also add nutrients, such as small peptides, to the substrate, which might be present at inadequate levels in the unfermented samples. Studies in the authors' laboratory showed that after fermentation, crude protein content was elevated and the crude fibre content of DDGS decreased (data not published). The improved nutritional value as a result of fermentation has already been demonstrated. However, it is unclear whether substituting FDDGS for DDGS can relieve negative effects on the performance and meat quality that result from supplementation of broilers with high levels of DDGS. Therefore, the present study was conducted to investigate the effects of replacing DDGS with FDDGS at high inclusion levels on growth performance, meat quality, and serum amino acid profile in broilers.

\section{Materials and Methods}

The experimental design and procedures in this study were reviewed and approved by the Animal Care and Use Committee of the College of Life Sciences and Environment, Hengyang Normal University.

A total of 48 Chinese yellow male broilers, with an initial bodyweight of $1.26 \pm 0.02 \mathrm{~kg}$, were randomly assigned to two treatments. Each treatment was replicated six times with four birds per replicate. Two diets were evaluated and each contained $80 \%$ of a basal diet, which was supplemented with $20 \%$ of either FDDGS or DDGS. The basal diet (Table 1) was formulated to meet NRC (1994) nutrient recommendations. The DDGS was a by-product of beer production and was provided by the Yanjing Beer Company (Yanjing, Hengyang, China). Fermentation of the DDGS was done in the authors' laboratory using Aspergillus niger, Saccharomyces cerevisiae, and Bacillus subtilis. The gross energy, protein, fat, crude fibre, and ash contents of the FDDGS were $4902 \mathrm{kcal} / \mathrm{kg}, 32.41 \%, 4.15 \%, 7.21 \%$ and $3.47 \%$ respectively. The corresponding proximate composition of the DDGS was $5180 \mathrm{kcal} / \mathrm{kg}$ gross energy, $24.90 \%$ protein, $3.92 \%$ fat, $14.67 \%$ crude fibre, and $3.99 \%$ ash. The amino acid compositions of the DDGS and FDDGS are shown in Table 2. The ammonia concentration in DDGS was 3.70\%, whereas in the FDDGS it was 0.99\%. Birds were housed in wire-floored suspended cages, and consumed feed and water on an ad libitum basis. The experiment was performed between April and May and lasted 28 days. Housing conditions were controlled by a natural ventilation system and there were two fans in the room. Natural lighting was applied during the experiment.

Bodyweight was recorded every week. Feed consumption could not be measured because of an indeterminate amount of feed wastage. At day 28, blood samples were collected from the wing vein and centrifuged $(2000 \times \mathrm{g}, 15 \mathrm{~min})$ at room temperature. The serum was then harvested and stored at $-80{ }^{\circ} \mathrm{C}$ until analysis. At the end of the four-week feeding period, six broilers from each treatment were randomly selected and euthanized by cervical dislocation. Abdominal fat, crureus, breast muscles, oesophagus, glandular stomach, muscular stomach, duodenum, jejunum, ileum, cecum, colorectum, bursal, spleen, and liver were separated and weighed. Breast and thigh muscles were sampled from the right side of carcass. Samples from the breast and thigh muscles were stored at $-4{ }^{\circ} \mathrm{C}$ for subsequent measurement of shear force. Additional samples of the breast and thigh muscles were stored at $-80^{\circ} \mathrm{C}$ until analysis.

The colour of the breast muscle was evaluated subjectively on a scale from 1 to 5 ( 1 = pale pinkish grey to white, and $5=$ dark purplish red) using a standard colorimetric board (Minolta, Osaka, Japan). A hand-held pH meter (Russell CD700, Russell pH Limited, Paisley, Scotland) was used to measure the pH of breast samples at 45 min post mortem. Drip loss of breast was determined by a suspension method. The breast muscle was weighed and placed in a plastic bag, suspended at $4{ }^{\circ} \mathrm{C}$ in a cooler for 24 hours and reweighed, and the percentage drip loss was calculated:

$$
\% \text { drip loss }=\frac{\text { final weight }- \text { initial weight }}{\text { initial weight }} \times 100
$$

The fresh breasts were weighed and baked in a steamer to a final internal temperature of $77^{\circ} \mathrm{C}$. The cooked breasts were cooled to ambient temperature, and reweighed. Cooking loss was calculated as a percentage of the weight that was lost based on the pre-cooking weight of breast. Breasts that were used to determine cooking loss were then used to calculate shear force. To measure the firmness, breasts were cut into squares $(20 \times 10 \times 10 \mathrm{~mm})$ and then subjected to the measurement of shear force using a digital tenderness meter (C-LM3B, Northeast Agricultural University, Harbin, China). Three shear force values were recorded for each bird and averaged. 
Table 1 Ingredients contained in the basal diet for broilers on as-fed basis, and its calculated nutrient content

\begin{tabular}{|c|c|}
\hline Ingredients, \% & Basal Diet \\
\hline Corn & 58.75 \\
\hline Soya bean meal $43 \% \mathrm{CP}$ & 26.40 \\
\hline Extruded full-fat soybean & 9.30 \\
\hline Soybean oil & 1.35 \\
\hline Limestone & 0.90 \\
\hline Dicalcium phosphate & 1.96 \\
\hline Premix $^{1}$ & 1.00 \\
\hline Salt & 0.34 \\
\hline \multicolumn{2}{|l|}{ Calculated values } \\
\hline $\mathrm{ME}, \mathrm{kcal} / \mathrm{kg}$ & 2950 \\
\hline CF, \% & 2.30 \\
\hline Crude fat, $\%$ & 5.40 \\
\hline $\mathrm{CP}, \%$ & 19.50 \\
\hline $\mathrm{Ca}, \%$ & 0.85 \\
\hline $\mathrm{P}, \%$ & 0.67 \\
\hline Digestible P, \% & 0.45 \\
\hline Salt, \% & 0.37 \\
\hline Lys, \% & 1.06 \\
\hline Met+Cys, \% & 0.70 \\
\hline Thr, \% & 0.81 \\
\hline Trp, \% & 0.24 \\
\hline
\end{tabular}

${ }^{1}$ Vitamin $A$ as retinyl acetate: $8065 \mathrm{IU}$; vitamin $\mathrm{D}_{3}$ as cholecalciferol: $1580 \mathrm{IU}$; vitamin $\mathrm{E}$ as DL-alpha tocopheryl acetate: $15 \mathrm{IU}$; riboflavin: $7.8 \mathrm{mg}$; vitamin $\mathrm{B}_{12}$ : $16 \mu \mathrm{g}$; D-pantothenic acid as D-calcium pantothenate: $12.8 \mathrm{mg}$; niacin: $75 \mathrm{mg}$; folic acid: $1.62 \mathrm{mg}$; biotin: $0.27 \mathrm{mg}$; choline chloride: $509 \mathrm{mg}$; copper as copper sulfate: $12 \mathrm{mg}$; iron as ferrous sulfate: $60 \mathrm{mg}$; iodine as ethylenediamine dihydriodide: $2.25 \mathrm{mg}$; manganese as manganese sulfate: $80 \mathrm{mg}$; selenium as sodium selenite: $0.15 \mathrm{mg}$; and zinc as zinc sulfate: $90 \mathrm{mg}$

Table 2 Amino acid concentrations for wheat-rice-based distillers dried grains with solubles and fermented distillers dried grains with solubles, indicated as standardized ileal digestible amino acids

\begin{tabular}{lcc}
\hline \multicolumn{1}{c}{ Amino acid } & $\begin{array}{c}\text { Fermented distillers dried grains } \\
\text { with solubles, } \%\end{array}$ & $\begin{array}{c}\text { Distillers dried grains } \\
\text { with solubles, \% }\end{array}$ \\
\hline Alanine & 2.02 & 1.80 \\
Arginine & 2.22 & 1.45 \\
Aspartic acid & 2.94 & 2.75 \\
Cysteine & 0.59 & 0.44 \\
Glutamic acid & 7.32 & 4.77 \\
Glycine & 1.54 & 1.46 \\
Histidine & 0.84 & 0.63 \\
Isoleucine & 1.57 & 1.38 \\
Leucine & 3.14 & 2.49 \\
Lysine & 1.62 & 1.27 \\
Methionine & 0.55 & 0.66 \\
Phenylalanine & 1.73 & 0.98 \\
Proline & 3.04 & 1.66 \\
Serine & 1.78 & 1.44 \\
Threonine & 1.39 & 1.23 \\
Tyrosine & 0.35 & 0.65 \\
Valine & 2.14 & 1.71 \\
\hline
\end{tabular}


Fresh meat samples were freeze-dried and then ground. Lipid concentrations of muscles were analysed by the Soxhlet extraction procedure using petroleum ether as the extraction agent (Soxhlet method 991.36) (AOAC, 2006). Crude protein concentrations of muscles were determined as the nitrogen content multiplied by 6.25 (method 968.06) (AOAC, 2006), using a CNS-200 carbon, nitrogen and sulphur analyser (LECO Corporation, St. Joseph, Missouri, USA). Fatty acid composition of the tissues was determined as follows. Briefly, total lipids were extracted using chloroform: methanol $(2: 1, \mathrm{v} / \mathrm{v})$ as extraction reagent. The fatty acid methyl esters (FAMEs) were prepared using a mixture of boron-trifluoride, hexane, and methanol (35: 20: $45 \mathrm{v} / \mathrm{v}$ ). FAME profiles were determined by Agilent 7890A gas chromatography equipped with SP2560 column (100 m x $250 \mu \mathrm{m} \times 0.2 \mu \mathrm{m})$ (Agilent Technologies Inc., Santa Rosa, CA). The gas chromatography conditions were as follows. The column oven temperature was set at $45^{\circ} \mathrm{C}$ for 4 min, raised to $175^{\circ} \mathrm{C}$ at a rate of $13^{\circ} \mathrm{C} / \mathrm{min}$, held at $175^{\circ} \mathrm{C}$ for $27 \mathrm{~min}$, increased from $175{ }^{\circ} \mathrm{C}$ to $215^{\circ} \mathrm{C}$ at a rate of $4{ }^{\circ} \mathrm{C}$ /min, and held at $215^{\circ} \mathrm{C}$ for $35 \mathrm{~min}$. The injector and detector temperatures were maintained at $250^{\circ} \mathrm{C}$. The carrier gas (hydrogen) flow rate was $30 \mathrm{~mL} / \mathrm{min}$. By comparing the FAME profile of the samples with those of FAME standards (Sigma Chemicals Co., St. Louis, MO), the fatty acid percentages were calculated relative to the total fatty acid content. Serum amino acid concentrations were analysed using oxidation analysis method on an Applied Biosystems 3200Q TRAP LC/MS/MS system equipped with RP-C18 column (150 mm length, $4.6 \mathrm{~mm}$ diameter, $5 \mathrm{~mm}$ particle size). Amino acid and fatty acid composition were tested in the Subtropical Institute of Chinese Academy of Sciences.

Treatment effects were determined by one-way analysis of variance using PROC GLM of SAS version 8.2 (SAS Inst. Inc., Cary, NC). Differences between mean values were evaluated using Tukey test at the level of $\mathrm{P}<0.05$.

\section{Results and Discussion}

No significant difference was noted in the average daily gain between FDDGS and DDGS groups $(P>$ 0.05 ) (Table 3). Corn DDGS is widely used in livestock production. It has been shown that adding $30 \%$ corn DDGS to finisher diets has no negative effect on the performance of Chinese yellow broilers (Ruan et al., 2017). In the present study, adding $20 \%$ wheat and rice-based DDGS as a supplement was not appropriate because broilers from both groups lost similar amounts of weight during the first week (result not shown). However, adaptation to these diets may explain this result, since subsequently the birds regained the lost weight. Based on digestible amino acid content, it has been reported that $20 \%$ DDGS from corn could be used in broiler diets (Wang et al., 2007), and 25\% DDGS has been found acceptable as well (Shim et al., 2011). Ten per cent DDGS has traditionally been the recommended limit for feeding broiler chickens during the grower period (Stein, 2007). Performance may be depressed at early age. However, subsequently the chicks have been able to tolerate this level of DDGS supplementation (Abudabos et al., 2017b). Unlike in the present study, use of fermented meal has been shown to improve the performance of broiler chickens compared with unfermented meal (Jazi et al., 2017; Dei et al., 2008).

Table 3 Growth of broilers fed diets supplemented with either $20 \%$ fermented distillers dried grains with solubles or $20 \%$ fermented distillers dried grains with solubles from 42 to 70 days old

\begin{tabular}{lrrrrr}
\hline & \multicolumn{2}{c}{ Supplement $^{1}$} & & \\
\cline { 2 - 3 } & \multicolumn{2}{c}{ FDDGS } & DDGS & SE & P-value \\
\hline Bodyweight, d 42, kg & 1.25 & 1.27 & 0.01 & 0.194 \\
Bodyweight, d 70, kg & 1.35 & 1.44 & 0.04 & 0.274 \\
Average daily gain, g/d & 14.00 & 12.84 & 1.58 & 0.726 \\
\hline
\end{tabular}

${ }^{1}$ FDDGS: fermented distillers dried grains with solubles, DDGS: distillers dried grains with solubles

No differences existed between FDDGS and DDGS treatments in the subjective incarnadine score, cooking loss, shear force, protein and fat content of breasts and thighs $(P>0.05)$ (Table 4). Breast muscle from broilers that were fed FDDGS had lower $\mathrm{pH}$ and lower percentage of drip loss than those from the DDGS treatment $(P<0.05)$. Feeding FDDGS to Chinese yellow broilers caused breast meat to be less acidic, which generally indicates higher quality meat. No comparable study was found that showed how FDDGS affects the $\mathrm{pH}$ of chicken meat. Schilling et al. (2010) found that feeding $12 \%-24 \%$ corn DDGS resulted in higher average at $\mathrm{pH} 24 \mathrm{~h}$ than in an unsupplemented control and 6\% corn DDGS treatment. However, other reports have shown that the addition of corn DDGS to a ration did not affect the $\mathrm{pH}$ value of breast meat in 
broilers (Ruan et al., 2017; Min et al., 2012). The increased pH may be related to altered glucose utilization in birds fed DDGS resulting in glycogen depletion. Previous reports have shown drip loss to be decreased after broilers consume DDGS (Min et al., 2012; Schilling et al., 2010). However, this result has not been entirely consistent across studies (Ruan et al., 2017). The present results confirm the finding that FDDGS can improve the water-holding capacity (WHC). It is well known that most water in the cell is held in myofibrils and that most water is retained (steric) by capillary forces generated by the arrangement of thick and thin filaments in the myofibril (Huff-Lonergan \& Lonergan, 2005). In addition, the decreased number of muscle fibres (Mazzoni et al., 2015) and increased fat content are likely to play a significant role in the reduction of WHC. As fat content of breast muscle was not affected by supplementation with FDDGS, the reason for greater WHC ability in this group may be ascribed to differences in the muscle fibres, but this needs further study.

Table 4 Quality of meat from broilers supplemented with either $20 \%$ fermented distillers dried grains with solubles or $20 \%$ fermented distillers dried grains with solubles from 42 to 70 days old

\begin{tabular}{|c|c|c|c|c|}
\hline \multirow[b]{2}{*}{ Quality indicator } & \multicolumn{2}{|c|}{ Supplement $^{1}$} & \multirow[b]{2}{*}{ SE } & \multirow[b]{2}{*}{$P$-value } \\
\hline & FDDGS & DDGS & & \\
\hline Subjective incarnadine score & 1.80 & 2.25 & 0.16 & 0.197 \\
\hline $\mathrm{Ph}$ & 5.30 & 6.00 & 0.14 & 0.046 \\
\hline Drip loss, \% & 0.96 & 1.48 & 0.11 & 0.048 \\
\hline Cooking loss, $\%$ & 26.72 & 26.23 & 0.89 & 0.794 \\
\hline Shear force, $\mathrm{kg}$ of force $/ \mathrm{cm}^{2}$ & 3.69 & 3.88 & 0.21 & 0.659 \\
\hline Protein content of thigh muscles, $\%$ & 0.46 & 0.52 & 0.02 & 0.273 \\
\hline Protein content of breast muscles, $\%$ & 0.62 & 0.58 & 0.01 & 0.324 \\
\hline Crude fat content of thigh muscles, & 7.92 & 8.91 & 0.32 & 0.082 \\
\hline Crude fat content of breast muscles, \% & 3.32 & 3.54 & 0.22 & 0.560 \\
\hline
\end{tabular}

${ }^{1}$ FDDGS: fermented distillers dried grains with solubles, DDGS: distillers dried grains with solubles

Only one of 15 fatty acids found in broiler thighs was significantly different between treatments (Table 5). Thighs from birds that were supplemented with FDDGS had less myristic acid (C14:0) than those from broilers that had been supplemented with DDGS $(P<0.05)$. In addition, birds that consumed FDDGS tended $(P<0.10)$ to have less elaidic acid $(\mathrm{C} 18: 1 \mathrm{n} 9 \mathrm{~T})$ compared with thighs from broilers that had been supplemented with DDGS. There were no significant differences between treatments in fatty acid composition in breast muscle (Table 6). Fatty acid composition of the feed is the most important determinant of the fatty acid composition in the resulting meat (Su et al., 2013). Jiang et al. (2014) found that the proportion of monounsaturated fatty acid in thigh meat decreased and the proportion of PUFA increased when the diet was supplemented with 15\% DDGS. An increased proportion of PUFA is may indicate increased susceptibility to oxidation. Thus, increasing the level of DDGS in the diets could make thigh meat more susceptible to oxidation. Including DDGS at $200 \mathrm{~g} / \mathrm{kg}$ in the diet has been shown to reduce the concentrations of stearic and behenic acids in thigh meat (Shim et al., 2018).

The effects of FDDGS supplementation on relative organ weights of broilers are shown in Table 7. Percentages of colorectum and large intestine were decreased in birds supplemented with FDDGS compared with those supplemented with DDGS $(P<0.05)$. Percentages of abdominal fat and oesophagus tended to be lower and percentages of the duodenum, spleen, and the small intestine tended to be greater in broilers supplemented with FDDGS compared with those supplemented with DDGS $(P<0.10)$. No differences between the treatments were detected for the percentages of crureus, breast muscles, glandular stomach, muscular stomach, jejunum, ileum, cecum, bursae and livers of broilers that were fed different diets $(P>0.10)$.

Feeding FDDGS decreased $(P<0.05)$ the concentrations of lysine, taurine, alpha-aminoadipic acid, glycine, and 3-Methylhistidine in the serum when compared with broilers that had been supplemented with DDGS (Table 8). Meanwhile, serum concentration of phosphoserine was greater for broiler Supplemented with FDDGS compared with DDGS $(P<0.05)$. However, was no differences were observed between treatments in serum concentration of histidine, threonine, valine, methionine, isoleucine, leucine, phenylalanine, arginine, urea, aspartic acid, serine, glutamic acid, sarcosine, alanine, $\beta$ - alanine, citrulline, $\alpha$ - 
aminobutyric acid, cysteine, cystathionine, tyrosine, $\beta$-aminoisobutyric acid, $\gamma$-aminobutyric acid, ethanolamine, hydroxylysine, ornithine, 1-methylhistidine, carnosine, anserine, proline, and hydroxyproline $(P>0.05)$.

Table 5 Fatty acid profile of meat from thighs of broilers supplemented with either $20 \%$ fermented distillers dried grains with solubles or $20 \%$ fermented distillers dried grains with solubles from 42 to 70 days old

\begin{tabular}{|c|c|c|c|c|}
\hline \multirow[b]{2}{*}{ Fatty acid, \% } & \multicolumn{2}{|c|}{ Supplement $^{1}$} & \multirow[b]{2}{*}{ SE } & \multirow[b]{2}{*}{$P$-value } \\
\hline & FDDGS & DDGS & & \\
\hline Myristic (C14:0) & 0.68 & 0.75 & 0.01 & 0.032 \\
\hline Palmitic (C16:0) & 23.42 & 24.59 & 0.52 & 0.299 \\
\hline Heptadecanoic (C17:0) & 0.29 & 0.30 & 0.01 & 0.765 \\
\hline Stearic (C18:0) & 9.11 & 9.09 & 0.25 & 0.965 \\
\hline Arachidic (C20:0) & 0.12 & 0.09 & 0.01 & 0.131 \\
\hline Palmitoleic (C16:1) & 3.46 & 3.41 & 0.16 & 0.868 \\
\hline Elaidic (C18:1n9T) & 0.16 & 0.19 & 0.01 & 0.095 \\
\hline Oleic (C18:1n9C) & 37.06 & 37.25 & 0.88 & 0.916 \\
\hline Eicosenoic (C20:1 n9) & 0.53 & 0.47 & 0.02 & 0.191 \\
\hline Linoleic (C18:2n6C) & 23.57 & 22.17 & 0.98 & 0.498 \\
\hline Y-Linolenic (C18:3n6) & 0.22 & 0.21 & 0.02 & 0.779 \\
\hline Homo-y-Linolenic (C20:3n6) & 0.26 & 0.31 & 0.03 & 0.401 \\
\hline Arachidonic (C20:4n6) & 0.14 & 0.13 & 0.02 & 0.672 \\
\hline$\alpha$-Linolenic (C18:3n3) & 0.75 & 0.87 & 0.04 & 0.195 \\
\hline Docosahexaenoic (C22:6n3) & 0.22 & 0.21 & 0.02 & 0.663 \\
\hline
\end{tabular}

${ }^{1}$ FDDGS: fermented distillers dried grains with solubles, DDGS: distillers dried grains with solubles

Table 6 Fatty acid profile of meat from the breast of broilers supplemented with either $20 \%$ fermented distillers dried grains with solubles or $20 \%$ fermented distillers dried grains with solubles from 42 to 70 days old

\begin{tabular}{|c|c|c|c|c|}
\hline \multirow[b]{2}{*}{ Fatty acid $^{a}, \%$} & \multicolumn{2}{|c|}{ Supplement $^{1}$} & \multirow[b]{2}{*}{ SE } & \multirow[b]{2}{*}{$P$-value } \\
\hline & FDDGS & DDGS & & \\
\hline Myristic (C14:0) & 0.58 & 0.64 & 0.02 & 0.182 \\
\hline Palmitic (C16:0) & 23.33 & 24.05 & 0.36 & 0.384 \\
\hline Heptadecanoic (C17:0) & 0.26 & 0.27 & 0.01 & 0.915 \\
\hline Stearic (C18:0) & 9.54 & 10.02 & 0.39 & 0.589 \\
\hline Arachidic (C20:0) & 0.10 & 0.10 & 0.01 & 0.639 \\
\hline Palmitoleic (C16:1) & 2.70 & 2.75 & 0.27 & 0.942 \\
\hline Elaidic (C18:1n9T) & 0.14 & 0.16 & 0.01 & 0.122 \\
\hline Oleic (C18:1n9C) & 32.30 & 33.16 & 1.05 & 0.710 \\
\hline Eicosenoic (C20:1 n9) & 0.90 & 0.75 & 0.20 & 0.729 \\
\hline Linoleic (C18:2n6C) & 20.89 & 19.58 & 0.89 & 0.515 \\
\hline y-Linolenic (C18:3n6) & 0.18 & 0.17 & 0.01 & 0.780 \\
\hline Homo-y-Linolenic (C20:3n6) & 0.37 & 0.47 & 0.08 & 0.588 \\
\hline Arachidonic (C20:4n6) & 7.27 & 5.97 & 0.61 & 0.353 \\
\hline a-Linolenic (C18:3n3) & 0.61 & 0.73 & 0.06 & 0.384 \\
\hline Docosahexaenoic (C22:6n3) & 0.80 & 0.68 & 0.14 & 0.691 \\
\hline
\end{tabular}

${ }^{1}$ FDDGS: fermented distillers dried grains with solubles, DDGS: distillers dried grains with solubles 
Table 7 Relative organ weights (\%) of broilers supplemented with either $20 \%$ fermented distillers dried grains with solubles or $20 \%$ fermented distillers dried grains with solubles from 42 to 70 days old

\begin{tabular}{lcccc}
\hline & \multicolumn{2}{c}{ Supplement $^{1}$} & Standard & \\
\cline { 2 - 3 } Organ & FDDGS & DDGS & error & P-value \\
\hline Abdominal fat & 1.62 & 2.29 & 0.14 & 0.052 \\
Crureus & 5.61 & 5.21 & 0.12 & 0.144 \\
Breast muscles & 4.72 & 4.90 & 0.29 & 0.763 \\
Oesophagus & 0.17 & 0.24 & 0.02 & 0.085 \\
Glandular stomach & 0.56 & 0.44 & 0.04 & 0.214 \\
Muscular stomach & 2.11 & 2.46 & 0.15 & 0.273 \\
Duodenum & 0.87 & 0.75 & 0.02 & 0.052 \\
Jejunum & 0.55 & 0.47 & 0.03 & 0.220 \\
Ileum & 0.47 & 0.46 & 0.02 & 0.812 \\
Cecum & 0.40 & 0.53 & 0.03 & 0.100 \\
Colorectum & 0.76 & 1.09 & 0.04 & 0.004 \\
Bursal & 0.10 & 0.10 & 0.01 & 0.872 \\
Spleen & 0.23 & 0.15 & 0.02 & 0.055 \\
Liver & 1.86 & 1.75 & 0.09 & 0.602 \\
Small intestine & 1.88 & 1.69 & 0.04 & 0.060 \\
Large intestine & 1.15 & 1.62 & 0.04 & 0.001 \\
\hline
\end{tabular}

${ }^{1}$ FDDGS: fermented distiller's dried grains with solubles, DDGS: distiller's dried grains with solubles

Previously, including DDGS in the diet of broilers decreased the digestibility of crude protein in meat from broilers (Kim et al., 2018). Fermentation has also increased digestibility of essential amino acids and other useful nutrients (Shi et al., 2015) and promoted muscle protein metabolism (Saleh et al., 2014). However, protein concentrations of both breast and thigh muscle were not affected by fermentation in the current study. Although the crude protein of the FDDGS was greater than that of DDGS, serum lysine content was reduced in the FDDGS supplemented group. This implies that the digestibility of amino acids was not improved by fermentation. Lysine, a-Aminoadipic acid, and phosphoserine are engaged in emotional regulation. Thus, stress behaviour might be more likely to occur in the FDDGS-supplemented group as serum lysine and a-Aminoadipic acid levels were reduced and the serum phosphoserine level was elevated in this group. These findings may be attributable to the lower fibre content of FDDGS, because previous studies have reported beneficial effects of fibre on satiety. 
Table 8 Free amino acid content of serum from broilers supplemented with either $20 \%$ fermented distillers dried grains with solubles or $20 \%$ fermented distillers dried grains with solubles from 42 to 70 days old

\begin{tabular}{|c|c|c|c|c|}
\hline \multirow[b]{2}{*}{ Amino acid, $\mu \mathrm{mol} / \mathrm{L}$} & \multicolumn{2}{|c|}{ Supplement $^{1}$} & \multirow[b]{2}{*}{ SE } & \multirow[b]{2}{*}{$P$-value } \\
\hline & FDDGS & DDGS & & \\
\hline Histidine & 6.74 & 9.07 & 0.89 & 0.265 \\
\hline Threonine & 13.07 & 19.82 & 2.12 & 0.184 \\
\hline Valine & 8.03 & 9.03 & 0.78 & 0.572 \\
\hline Methionine & 5.96 & 4.22 & 0.46 & 0.123 \\
\hline Isoleucine & 4.41 & 4.50 & 0.26 & 0.874 \\
\hline Leucine & 10.19 & 12.49 & 0.98 & 0.310 \\
\hline Phenylalanine & 8.61 & 9.12 & 0.61 & 0.707 \\
\hline Lysine & 12.23 & 19.88 & 1.04 & 0.014 \\
\hline Arginine & 21.83 & 24.84 & 1.73 & 0.443 \\
\hline Taurine & 9.59 & 12.96 & 0.30 & 0.002 \\
\hline Urea & 4.95 & 4.14 & 0.56 & 0.522 \\
\hline Aspartic acid & 5.61 & 5.23 & 0.51 & 0.738 \\
\hline Serine & 35.12 & 32.53 & 1.74 & 0.510 \\
\hline Phosphoserine & 2.29 & 1.72 & 0.10 & 0.035 \\
\hline Glutamic acid & 13.83 & 17.76 & 1.16 & 0.162 \\
\hline Sarcosine & 0.62 & 0.88 & 0.05 & 0.065 \\
\hline a-Aminoadipic acid & 0.19 & 0.39 & 0.03 & 0.012 \\
\hline Glycine & 16.88 & 26.10 & 1.34 & 0.018 \\
\hline Alanine & 33.20 & 29.48 & 1.67 & 0.335 \\
\hline$\beta$-Alanine & 1.73 & 2.11 & 0.18 & 0.357 \\
\hline Citrulline & 1.22 & 1.52 & 0.11 & 0.266 \\
\hline a-Aminobutyric acid & 1.46 & 1.84 & 0.21 & 0.435 \\
\hline Cysteine & 3.65 & 4.41 & 0.40 & 0.410 \\
\hline Cystathionine & 0.90 & 1.15 & 0.10 & 0.273 \\
\hline Tyrosine & 13.15 & 11.20 & 1.29 & 0.501 \\
\hline$\beta$-Aminoisobutyric acid & 0.91 & 1.05 & 0.11 & 0.554 \\
\hline Y-Aminobutyric acid & 0.13 & 0.13 & 0.02 & 1.000 \\
\hline Ethanolamine & 1.08 & 1.22 & 0.14 & 0.657 \\
\hline Hydroxylysine & 0.12 & 0.19 & 0.00 & 0.050 \\
\hline Ornithine & 1.25 & 1.37 & 0.07 & 0.470 \\
\hline 1-Methylhistidine & 6.31 & 4.33 & 1.05 & 0.407 \\
\hline 3-Methylhistidine & 1.33 & 2.24 & 0.15 & 0.032 \\
\hline Carnosine & 2.22 & 3.40 & 0.30 & 0.116 \\
\hline Anserine & 4.22 & 7.94 & 0.75 & 0.057 \\
\hline Proline & 12.50 & 16.99 & 1.00 & 0.078 \\
\hline Hydroxyproline & 2.65 & 5.30 & 0.59 & 0.076 \\
\hline
\end{tabular}

${ }^{1}$ FDDGS: fermented distiller's dried grains with solubles, DDGS: distiller's dried grains with solubles

\section{Conclusion}

Relatively minor differences were observed in the performance, meat quality, relative organ weights, fatty acid profiles and amino acid profiles of the meat from broilers whose diets had been supplemented with either FDDGS or DDGS. These processed by-products of the brewing industry as sources of protein can be used as equivalent sources of protein in the diet of broiler chickens.

\section{Acknowledgments}

This research was supported by Applied Basic Research Programs of Science and Technology Foundation of HuNan Province (No. 2016JC2034), Research Foundation of the Education of Hunan Province (18B373) and China postdoctoral science foundation funded project (No.2016M600630). 


\section{Authors' contributions}

CY conceived the experiment and drafted the initial manuscript. CY and XT contributed equally to this study and they jointly conducted the animal experiment and the laboratory analyses. HY, QT, JT and DB provided advice on the experiment and reviewed the manuscript. All authors read and approved the final manuscript.

\section{Conflict of interest declaration}

The authors have no conflict of interest relative to the work reported in this paper.

\section{References}

Abudabos, A.M., Al-Atiyat, R.M. \& Khan, R.U., 2017a. A survey of mycotoxin contamination and chemical composition of distiller's dried grains with solubles (DDGS) imported from the USA into Saudi Arabia. Environ. Sci. Poll. Res. 24(18), 1-5.

Abudabos, A.M., Al-Atiyat, R.M., Stanley, D., Aljassim, R. \& Albatshan, H.A., 2017b. The effect of corn distillers dried grains with solubles (DDGS) fortified with enzyme on growth performance of broiler. Environ. Sci. Poll. Res. 24(26), 1-10.

Association of Official Analytical Chemists (AOAC). 2006. Official methods of analysis. 18th ed. AOAC, Gaithersburg, MD.

Barekatain M., Antipatis C., Rodgers N., Walkden-Brown S., lji, P. \& Choct, M., 2013. Evaluation of high dietary inclusion of distillers dried grains with solubles and supplementation of protease and xylanase in the diets of broiler chickens under necrotic enteritis challenge. Poult. Sci. 92, 1579-1594.

Dei, H.K., Rose, S.P., Mackenzie, A.M. \& Amarowicz, R., 2008. Growth performance of broiler chickens fed diets containing shea nut (Vitellaria paradoxa, gaertn.) meal fermented with Aspergillus niger. Poul. Sci. 87(9), 1773-1778.

Huff-Lonergan, E. \& Lonergan, S.M., 2005. Mechanisms of water holding capacity of meat: The role of postmortem biochemical and structural changes. Meat Sci. 71,194-204.

Jazi, V., Boldaji, F., Dastar, B., Hashemi, S.R. \& Ashayerizadeh A., 2017. Effects of fermented cottonseed meal on the growth performance, gastrointestinal microflora population and small intestinal morphology in broiler chickens. Brit. Poult Sci. 58(4), 402-408.

Jiang, W., Nie, S., Qu, Z., Bi, C. \& Shan, A., 2014. The effects of conjugated linoleic acid on growth performance, carcass traits, meat quality, antioxidant capacity, and fatty acid composition of broilers fed corn dried distillers grains with solubles. Poult. Sci. 93(5), 1202-1206.

Kim, J.S., Hosseindoust, A.R., Shim, Y.H., Lee, S.H., Choi, Y.H. \& Kim, M.J., 2018. Processing diets containing corn distillers dried grains with solubles in growing broiler chickens: Effects on performance, pellet quality, ileal amino acids digestibility, and intestinal microbiota. Poult. Sci. 97, 2411-2418.

Mazzoni, M., Petracci, M., Meluzzi, A., Cavani, C., Clavenzani, P. \& Sirri F., 2015. Relationship between pectoralis major muscle histology and quality traits of chicken meat. Poult. Sci. 94,123-130.

Min, Y.N., Li, L., Waldroup, P.W., Niu, Z.Y., Wang, Z.P., Gao, Y.P. \& Liu, F.Z., 2012. Effects of dietary distillers dried grains with solubles concentrations on meat quality and antioxidant status and capacity of broiler chickens. J. Appl. Poult. Res. 21, 603-611.

Ruan, D., Jiang S.Q., Hu, Y.J., Ding, F.Y., Fan, Q.L. \& Chen, F., 2017. Effects of corn distillers dried grains with solubles on performance, oxidative status, intestinal immunity and meat quality of Chinese yellow broilers. J. Anim. Phys. Anim. Nutr. 101(6), 1185-1193.

Saleh, A.A., Amber, K., Elmagd, M.A., Atta, M.S., Mohammed, A.A. \& Ragab, M.M., 2014. Integrative effects of feeding aspergillus awamori and fructooligosaccharide on growth performance and digestibility in broilers: Promotion muscle protein metabolism. Biomed Res. Int. 2014(1), 946859.

Schilling, M.W., Battula, V., Loar, R.E., Jackson, V., Kin, S. \& Corzo, A., 2010. Dietary inclusion level effects of distillers dried grains with solubles on broiler meat quality. Poult. Sci. 89, 752-760.

Shi, C.Y., He, J., Jie, Y., Bing, Y., Huang, Z. \& Mao, X., 2015. Solid state fermentation of rapeseed cake with aspergillus niger for degrading glucosinolates and upgrading nutritional value. J. Anim. Sci. Biotech. 6(3), 1-7.

Shim, M.Y., Pesti, G.M., Bakalli, R.I., Tillman, P.B., \& Payne, R.L., 2011. Evaluation of corn distillers dried grains with solubles as an alternative ingredient for broilers. Poult. Sci. 90, 369-376.

Shim, Y.H., Kim, J.S., Hosseindoust, A., Choi, Y.H., Kim, M.J. \& Oh, S.M., 2018. Investigating meat quality of broiler chickens fed on heat processed diets containing corn distillers dried grains with solubles: Korean J. Food Sci. Anim. Res. 38(3), 629-635.

Stein, H.H., 2007. Distillers dried grains with solubles (DDGS) in diets fed to swine. Swine Focus 1, 1-8.

Stein, H.H. \& Shurson, G.C., 2009. Board-invited review: the use and application of distillers dried grains with solubles in swine diets. J. Anim. Sci. 87, 1292-1303.

Su, B.C., Wang, L.S., Wang, H., Shi, B.M., Shan, A.S. \& Li, Y.Z., 2013. Conjugated linoleic acid and betain prevent pork quality issues from diets containing distillers dried grains with solubles. Can. J. Anim. Sci. 93, 477-485.

Wang, Z., Cerrate, S., Coto, C., Yan, F. \& Waldroup, P.W., 2007. Utilization of distillers dried grains with solubles (DDGS) in broiler diets using a standardized nutrient matrix. Int. J. Poult. Sci. 6, 470-477. 